\title{
WILEY-VCH
}

DOI: $10.1002 /$ ((please add manuscript number))

Article type: Full Paper

\section{Al-, Ga-, and In-doped ZnO thin films via aerosol assisted CVD for use as transparent conducting oxides}

Dominic B. Potter, Davinder S. Bhachu, Michael J. Powell, Jawwad A. Darr, Ivan P. Parkin, Claire J. Carmalt*

D. B. Potter, Dr. D. S. Bhachu, Dr. M. J. Powell, Prof. J. A. Darr, Prof. I. P. Parkin, Prof. C. J. Carmalt

Materials Chemistry Centre, Department of Chemistry, University College London, WC1H OAJ, UK

E-mail: c.j.carmalt@ucl.ac.uk

Keywords: (transparent conducting oxides, aerosol assisted, chemical vapor deposition, zinc oxide, doping)

Al-, Ga-, and In-doped $\mathrm{ZnO}$ thin films were deposited on glass substrates by aerosol assisted chemical vapour deposition (AACVD) at a deposition temperature of $450{ }^{\circ} \mathrm{C}$. The air-stable compound zinc acetylacetonate $\left[\mathrm{Zn}(\mathrm{acac})_{2}\right]$ was used as a $\mathrm{Zn}$ source, whilst for the dopants of $\mathrm{Al}, \mathrm{Ga}$ and In, the corresponding trichloride was used. Methanol solutions of the metal salts were used as precursor solutions and $\mathrm{N}_{2}$ carrier gas was used for the aerosol. Films were grown in approximately 30 minutes and were synthesised using dopant values of 5, 10, 15 and $20 \mathrm{~mol} \%$ (with respect to the $\mathrm{Zn}$ ) in the precursor solution. XRD analysis showed that the films were wurtzite $\mathrm{ZnO}$. XPS analysis confirmed the presence of the dopants in the films. Several of the films showed high transparency (>80\%) in the visible range, and low resistivity $\left(\sim 10^{-3} \Omega \cdot \mathrm{cm}\right)$.

\section{Introduction}

Transparent conducting oxides (TCOs) are an important component in a broad range of optoelectronic and consumer devices. ${ }^{[1,2]}$ They are a class of semiconductors that possess the desirable characteristics of low electrical resistivity $\left(\sim 10^{-3}-10^{-4} \Omega \cdot \mathrm{cm}\right)$ as well as a high optical transparency towards visible light (>80\% transmittance), due to their wide band gap 


\section{WILEY-VCH}

$(>3 \mathrm{eV})$. Currently, the most commonly used TCO material in industry is tin-doped indium oxide, also known as indium tin oxide (ITO). Undoped indium oxide is a wide bandgap material $\left(\mathrm{E}_{\mathrm{g}} \sim 3.75 \mathrm{eV}\right.$ at room temperature), which allows for high transparency of visible light. The bandgap has been shown to increase up to $\sim 4.2 \mathrm{eV}$ as the film was doped with 5 $\mathrm{wt} \% \mathrm{Sn}$. This is the result of an increase in the carrier concentration, leading to the BursteinMoss effect. ${ }^{[3,4]}$ Increasing the Sn content further resulted in a slight decrease in the band gap to $\sim 4.1 \mathrm{eV}$. This was attributed to the excess $\mathrm{Sn}$ causing crystal disorder, as well as acting as carrier traps rather than electron donors due to the formation of impurity phases such as $\mathrm{Sn}_{2} \mathrm{O}$, $\mathrm{Sn}_{2} \mathrm{O}_{4}$, and $\mathrm{SnO}{ }^{[5]}$ ITO thin films are n-type semiconductors, meaning delocalised electrons are the majority charge carrier. Highly conductive ITO films have been synthesised with restistivities as low as $10^{-5} \Omega \cdot \mathrm{cm}$, carrier concentrations on the order of $10^{21} \mathrm{~cm}^{-3}$ and Hall mobilities which are in the range ca. 30 to $100 \mathrm{~cm}^{2} / \mathrm{V} \cdot \mathrm{s} .{ }^{[6-9]}$

Another commonly used TCO material is fluorine-doped tin oxide, also known as fluorine tin oxide (FTO). FTO films maintain the rutile structure of bulk tin oxide $\left(\mathrm{SnO}_{2}\right)$ and, analogous to ITO films, doping with fluorine results in an increase in the lattice parameter. ${ }^{[10,11]}$ Undoped tin oxide has a bandgap of $\sim 3.6 \mathrm{eV}$ at room temperature. ${ }^{[12]}$ Doping with fluorine has been shown to increase the bandgap to $\sim 4.2 \mathrm{eV}$ at room temperature, again due to the Burstein-Moss effect. ${ }^{[13]}$ Like ITO, FTO films are n-type semiconductors. Highly conductive FTO films have been synthesised with resistivities as low as $10^{-4} \Omega \cdot \mathrm{cm}$, carrier concentrations on the order of $10^{20} \mathrm{~cm}^{-3}$, and Hall mobilities which are in the range ca. 1 to $20 \mathrm{~cm}^{2} / \mathrm{V} \cdot \mathrm{s}{ }^{[14-17]}$ As a result of their increasing scarcity, the cost of indium and $\operatorname{tin}^{[18]}$ is currently very high, which has led to a search for substitute TCO materials based on more sustainable metals. A promising more sustainable, less toxic and inexpensive alternative TCO material class are doped zinc oxides, due to their wide band gap $(\mathrm{Eg} \sim 3.3 \mathrm{eV} \text { at room temperature })^{[19]}$. Previously, Al-, Ga-, and In-doped ZnO thin films with properties comparable to those of ITO 


\section{WILEY-VCH}

and FTO, have been synthesised by various techniques, including pulsed laser deposition (PLD) and by chemical vapour deposition (CVD). ${ }^{[19-25]}$ Additionally, due to a much higher natural abundance of $\mathrm{Zn}$ in comparison to both $\mathrm{In}$ and $\mathrm{Sn},{ }^{[26]}$ there is a wide selection of relatively inexpensive $\mathrm{Zn}$-containing precursors available. This means that effective $\mathrm{ZnO}$ based TCO materials can be deposited inexpensively.

The present synthesis techniques used in industry for preparing TCO thin films are spray pyrolysis, sputtering, sol-gel evaporation, and chemical vapour deposition (CVD). ${ }^{[27]}$ CVD is a method regularly employed to produce thin film coatings. It involves the vaporisation of volatile precursors, usually by heating them to high temperatures in a bubbler. The vaporised precursors are then transported via a carrier gas to a heated substrate. Aerosol assisted chemical vapour deposition (AACVD) is a variation of CVD, whereby a solution containing the precursors is prepared, which is then aerosolised, before being transported to the substrate. The AACVD method is of particular interest, as it has important advantages over conventional CVD methods, such as atmospheric pressure (AP)CVD. APCVD involves the evaporation of the precursors and thus relies on the usage of volatile precursor compounds. Since AACVD involves dissolving the precursors in a solvent prior to aerosolisation, the solubility is the important requirement of the precursors, rather than volatility. This is significant because a wide range of alternative precursors can be used, particularly if there are no suitable precursors available for APCVD. The simplicity through which thin films can be inexpensively synthesised using AACVD makes it a strong candidate for industrial TCO thin film production. Additionally, the morphology of the film can be controlled by varying the precursors and solvent used to make up the precursor solution. ${ }^{[17,28]}$ Another advantage is that AACVD is usually performed using a single-source solution, in which the precursors undergo complete molecular mixing. This allows for potential control of stoichiometry during the synthesis of multicomponent materials. ${ }^{[29]}$ Finally, AACVD is a relatively inexpensive 


\section{WILEY-VCH}

process, as it simplifies the precursor vapour generation and delivery processes in comparison to APCVD. It can also be conducted in an open atmosphere, and thus it does not require a complicated reactor system.

In comparison to many other deposition techniques, AACVD is a simple, effective method through which high quality thin films can be synthesised. It is for this reason that AACVD is a potential candidate for depositing industrial-scale coatings (often continuous ribbons, several metres across) onto large glass substrates.

Herein, electrically conductive and optically transparent Al-, Ga-, and In-doped $\mathrm{ZnO}$ thin films were prepared by AACVD, using inexpensive precursors.

\section{Results and Discussion}

\subsection{Film Synthesis}

Al-, Ga-, and In-doped $\mathrm{ZnO}$ thin films were successfully deposited onto a glass substrate via AACVD, using a precursor solution consisting of $\mathrm{Zn}(\mathrm{acac})_{2}$ and the corresponding group 13 chlorides in methanol. Notably, $\mathrm{Zn}(\mathrm{acac})_{2}$ can be purchased commercially at a lower cost than other commonly used zinc precursors, including diethyl zinc, ${ }^{[30]}$ zinc acetate, ${ }^{[31]}$ and $\mathrm{Zn}(\mathrm{thd})_{2}$ (thd = 2,2,6,6-tetramethyl-3,5-heptadionate). ${ }^{[24]}$ Additionally, diethyl zinc, the most widely used zinc precursor, is a pyrophoric substance, which makes its usage dangerous and nontrivial. $\mathrm{Zn}(\mathrm{acac})_{2}$ is air stable and thus safer to handle, making it potentially attractive for industrial use in the future.

All of the prepared films showed high adherence to the glass substrate and passed the Scotch tape test and resisted scratching with a scalpel. A summary of film properties is provided in Table 1. They appeared visually optically transparent and when observed at an angle, displayed interference patterns, indicating the film thickness was comparable to the 


\section{WILEY-VCH}

wavelength of visible light. ${ }^{[32]}$ The actual film thicknesses were acurately determined by examining the films by side-on SEM. These thicknesses are presented in Table 1.

\subsection{XRD Analysis}

All of the as-prepared films consisted of a $\mathrm{ZnO}$-like hexagonal wurtzite structure, as shown by $\mathrm{XRD}$ (Figure 1). The undoped $\mathrm{ZnO}$ film displayed a strongly preferred orientation in the (002) plane. The Al-doped films and Ga-doped films both displayed similar trends, in which preferred orientation remained in the (002) plane, but a loss in peak intensity could be observed upon increasing the concentration of the dopant in the precursor solution. This preferred orientation, perpendicular to the substrate surface, has previously been observed in $\mathrm{ZnO}$ thin films prepared by other methods. ${ }^{[31,33]}$ However, upon doping with 5 mol\% In, the preferred orientation in this direction was not observed and the intensity of the (002) peak diminished further with increasing In concentration. Instead, the In-doped $\mathrm{ZnO}$ films showed a preferred orientation in the (100) and (101) directions. This trend has been previously observed in In-doped $\mathrm{ZnO}$ films prepared by spray pyrolysis. ${ }^{[34-36]}$

Increasing the concentration of each dopant also resulted in a decrease in the relative intensity of the (102) and (103) peaks. Overall, the maximum peak intensities diminished at higher doping concentrations, indicating disorder in the crystal structure. This could be due to the incorporation of the dopants. As the dopant atoms possess different ionic radii to that of $\mathrm{Zn}$, their substitution into $\mathrm{Zn}$ sites (or interstitial sites) will likely cause strain within the lattice. The loss in XRD peak intensity due to disorder upon doping, which usually coincides with a reduction in electrical conductivity, is a commonly observed phenomenon in thin film semiconductors. $^{[11,37-40]}$

Additionally, the unit cell volumes were calculated using GSAS and EXPGUI, and are shown in Table 1.

\subsection{XPS Analysis}




\section{WILEY-VCH}

XPS analysis showed the presence of $\mathrm{Zn}$ in each film, as well as the presence of the respective dopants. Additionally, it was observed that the dopant:Zn ratio in the precursor solution was not the same as the dopant: $\mathrm{Zn}$ ratio in the resultant film. However, increasing the dopant concentration in the precursor solution generally did give rise to an increase in the amount of dopant at the surface of the film. These values are given in Table 1. Note that the values in the table do not indicate the absolute concentration of dopant, but rather the relative amount in comparison to $\mathrm{Zn}$. The Al-doped films showed a relatively high quantity of $\mathrm{Al}$ at the surface, particularly when $15-20 \mathrm{~mol} \% \mathrm{Al}$ was added to the precursor solution. The higher concentration of dopant at the surface coincides with a decrease in conductivity (Table 1). This could indicate the formation of a small secondary phase of non-conductive aluminium oxide $\left(\mathrm{Al}_{2} \mathrm{O}_{3}\right)$ at the surface.

\subsection{UV-Vis Analysis}

All of the as-prepared films displayed high optical transparency in the visible range, with several of them showing $>80 \%$ transmittance in the $400-700 \mathrm{~nm}$ range of wavelengths. The transmittance reduced at longer wavelengths, which indicated a greater absorption of infrared (IR) radiation in comparison to visible light. The reflectance spectra displayed interference patterns in the visible range, which is common for high refractive index films, and is because the photons that reflected from the air-film boundary interfered with the photons that reflected from the film-substrate boundary, which resulted in regions of constructive and destructive interference. ${ }^{[41-43]}$ When examining the films by eye, the visible interference patterns were spread across the entire film coating the substrate. The change in colour within these patterns when observed off-angle indicated the unavoidable variation in film thickness across the substrate, which is due to the nature of the side-on AACVD technique.

For each dopant, the average transmittance in the visible range increased with the amount of dopant in the precursor solution, with $15 \mathrm{~mol} \%$ of dopant in the solution resulting in the most 


\section{WILEY-VCH}

transparent film, before a subsequent decrease in the transmittance at $20 \mathrm{~mol} \%$.

Doping with Ga resulted in the most transparent films (Figure 2). The most transparent film prepared herein was using a $15 \mathrm{~mol} \%$ Ga dopant in the precursor mixture, which displayed an average transmittance of $84.4 \%$ in the visible part of the spectrum. This is significant, since a requirement for industrial standard TCOs is that they possess an average transmittance $>80 \%$ across the optical range of wavelengths.

The transmission-reflectance spectra of the films were used to produce Tauc plots, from which band gap energies $\left(E_{\mathrm{g}}\right)$ were obtained (Table 1). For each type of dopant, it was found that the band gap widened with increasing dopant concentration, before narrowing again at when using $20 \mathrm{~mol} \%$ dopant. The initial increase is due to the Burstein-Moss effect, whereby an increase in dopant electrons causes electrons to occupy states at the bottom of the conduction band, thus raising the Fermi level and widening the band gap. The reduction in band gap energy at higher dopant concentration can be attributed to the increase in electronelectron and electron-dopant interactions. ${ }^{[44,45]}$ The wide band gaps contribute towards the high optical transmittance of the films.

\subsection{SEM Analysis}

SEM was used to observe the surface morphology of the films deposited using a $10 \mathrm{~mol} \%$ precursor solution. The surface morphology of the films was shown to vary, depending on the dopant used (Figure 3). The Al- and Ga-doped films had a highly textured surface, consisting of a hexagonal grain structure. The preferred orientation of the grains can clearly be seen, with the (002) surface facing outwards, and the columnar growth of the grains being visible. This agrees with the preferred orientation observed in the corresponding XRD data (Figure 1). In the case of the Al-doped film, the grains appear to have been etched, resulting in a more textured film than the Ga-doped film. ${ }^{[30,46]}$ The In-doped film was the least textured of the three, and consisted of smooth, well-connected grains, with particle diameters smaller than 


\section{WILEY-VCH}

those found in the Al- and Ga-doped films.

EDX analysis was conducted on each of the films prepared using $10 \mathrm{~mol} \%$ dopant. Note that, like the values given by XPS, these values are not absolute concentrations, but rather the amount of dopant relative to $\mathrm{Zn}$. It indicated that for the $10 \mathrm{~mol} \% \mathrm{Al}$-doped film, there was ca. 10.5 atm\% dopant in the bulk of the film. This value is significantly less than the surface concentration of 33.4 atm\% dopant as suggested by XPS analysis (Table 1), indicating there was significant segregation of the dopant to the uppermost few nanometres of this film. Conversely, EDX analysis of the $10 \mathrm{~mol} \%$ In dopant sample revealed only 7.2 atm\% dopant in the bulk of the film, which was higher than the surface value of $1.3 \mathrm{~atm} \%$ (as indicated by XPS), suggesting the dopant had preferentially formed away from the surface. For the 10 mol\% Ga dopant sample, EDX analysis of the bulk of the film suggested a value of 15.5 atm\% dopant. This was within the range of error of the surface quantity suggested by XPS, which was 16.8 atm\%, thus indicating Ga was most likely to be uniformly distributed throughout the entire film. These trends were each confirmed by etching into the films and reexamining by XPS.

\subsection{Conductivity Measurements}

The van der Pauw method ${ }^{[47]}$ was used to determine the sheet resistance $(\rho)$, free carrier concentration $(\mathrm{N})$ and carrier mobility $(\mu)$ for each film. The results are summarised in Table 1. The films with lowest resistivities were found for the films doped with $10 \mathrm{~mol} \%$ of dopant. The most conductive film was $10 \mathrm{~mol} \%$ Al-doped $\mathrm{ZnO}$, which had a resistivity of $5.0 \times 10^{-3}$ $\Omega \cdot \mathrm{cm}$.

The electrical properties of the films prepared in this work are comparable to other reports of doped $\mathrm{ZnO}$ films synthesised by similar methods. ${ }^{[24,30,46,48,49]}$ Recently, Kuprenaite et al. prepared $\mathrm{Al}$-doped $\mathrm{ZnO}$ thin films on glass substrates via AACVD at a deposition temperature of $400{ }^{\circ} \mathrm{C}$, and achieved a much higher resistivity of $2.83 \Omega \cdot \mathrm{cm}$, for a doping level of $3 \mathrm{~atm} \%$ 


\section{WILEY-VCH}

A1. ${ }^{[24]}$ Both Bhachu et al. and Ponja et al. prepared Al-doped $\mathrm{ZnO}$ thin films on glass via AACVD at a deposition temperature of $450{ }^{\circ} \mathrm{C}$, and obtained improved resistivities; however, the precursors used in each case were highly pyrophoric (diethyl zinc and trimethyl aluminium), which made the synthesis procedure non-trivial and dangerous. ${ }^{[30,46]}$ The films prepared in this work utilised much safer, more air-stable precursors. Chen et al. recently prepared Ga-doped $\mathrm{ZnO}$ thin films on glass substrates via AACVD at a deposition temperature of $450{ }^{\circ} \mathrm{C}$, and obtained a minimum resistivity value of $2.3 \times 10^{-2} \Omega \cdot \mathrm{cm}$, which was higher than the minimum resistivity value obtained for the Ga-doped films prepared in this work. ${ }^{[48]}$ Similarly, Nolan et al. prepared a 3 atm\% In-doped $\mathrm{ZnO}$ film on glass via AACVD at $425^{\circ} \mathrm{C}$. The resistivity for this film was $7.2 \times 10^{-2} \Omega \cdot \mathrm{cm}$, which was higher than the minimum resistivity value obtained for the In-doped films prepared in this work. ${ }^{[49]}$

The resistivity of the films prepared in this work was shown to increase significantly at high dopant concentrations (Table 1). This is due to a combination of factors, including a loss of long range crystal order, as indicated by the XRD patterns (Figure 1), as well as an increase in impurity scattering due to the high concentration of charged dopant atoms in the film. The bulk carrier concentration also peaked for the 5 or $10 \mathrm{~mol} \%$ doped films, and was on the order of $10^{20} \mathrm{~cm}^{-3}$. The initial increase in carrier concentration was due to delocalisation into the conduction band of the electrons supplied by the aliovalent dopant atoms. The decrease in carrier concentration at high doping concentrations can be attributed to the excess dopant atoms acting as carrier sinks rather than carrier sources. The carrier mobility was largely unaffected by the dopant concentration, and did not seem to show a significant trend.

Overall, the electrical properties of the films are extremely good, with the resistivity being comparable to other doped $\mathrm{ZnO}$ thin films prepared previously in similar conditions. ${ }^{[24,30,46,48 \text {, }}$ ${ }^{49]}$ These results are especially promising when considering the ease of preparation, as well as the far safer precursors used for the deposition in comparison to other attempts to prepare 


\section{WILEY-VCH}

doped $\mathrm{ZnO}$ TCOs.

\section{Conclusion}

Al-, Ga-, and In-doped $\mathrm{ZnO}$ thin films were synthesised using AACVD, the air stable and relatively inexpensive compound $\mathrm{Zn}(\mathrm{acac})_{2}$ as the $\mathrm{Zn}$ precursor and the group- 13 chlorides as the dopant precursors. To the best of our knowledge, this is the first time this combination of precursors have been used for this method to produce doped $\mathrm{ZnO}$ TCOs. The films were highly adherent to the glass substrate, optically transparent (>80\% transmittance), and highly electrically conductive $\left(\sim 10^{-3} \Omega \cdot \mathrm{cm}\right)$, especially in comparison to previous attempts to prepare doped $\mathrm{ZnO}$ TCOs by similar methods. XRD analysis showed that the films had the same wurtzite structure as bulk $\mathrm{ZnO}$. The $\mathrm{Al}-$, and Ga-doped films showed preferred orientations in the (002) direction, whereas the In-doped films showed preferred orientation in the (100) and (101) directions. XPS analyses indicated the presence of $\mathrm{Zn}$ and the respective dopant in each film. Comparison of XPS and EDX data suggested that Al-doping resulted in segregation of the dopant towards the surface, whereas In-doping resulted in segregation of the dopant away from the surface. Ga-doping resulted in a consistent dopant concentration throughout the bulk of the film.

Increasing the dopant concentration in the precursor solution resulted in a higher concentration of dopant in the resultant film. The films with $10 \mathrm{~mol} \%$ of dopant were the most conductive for each dopant element, as they possessed a low resistivity, high carrier concentration, and had a highly crystalline structure.

The high quality films synthesised in this work were prepared using air stable precursors via AACVD, which is an efficient, reproducible method, and allows for easy control over dopant concentration. As such, this process has the potential to be scaled up to prepare industrialscale TCO coatings. 


\section{WILEY-VCH}

\section{Experimental Section}

\subsection{Film Synthesis}

Depositions were carried out under nitrogen (99.99\% from BOC). All other chemicals were purchased from Sigma Aldrich, and used as bought.

A typical precursor solution was prepared by dissolving $\mathrm{Zn}(\mathrm{acac})_{2}(0.5 \mathrm{~g}, 1.90 \mathrm{mmol})$ in methanol (20 mL), followed by dissolving a dopant quantity of $\mathrm{AlCl}_{3} / \mathrm{GaCl}_{3} / \mathrm{InCl}_{3}$ to give a dopant level of 5, 10, 15 or $20 \mathrm{~mol} \%$ with respect to zinc. Hereafter, any value of mol\% will refer to precursor solution content, unless stated otherwise. Several drops of acetic acid were added to improve the solubility of the solid precursors. The precursor solution was stirred for 10 mins, before being transferred to a glass bubbler. The substrate used was a standard float glass plate $(15 \mathrm{~cm} \times 4 \mathrm{~cm} \times 0.3 \mathrm{~cm})$, precoated with a $\mathrm{SiO}_{2}$ barrier layer $(\mathrm{ca} .50 \mathrm{~nm})$, from Pilkington's NSG (Wigan, Lancashire, UK). The barrier layer was necessary to prevent ions from leaching between the glass substrate and the TCO film. The glass was laid horizontally on top of a graphite heating block, and heated inside a quartz tube, with a top plate suspended above it to ensure laminar flow of the aerosol. An aerosol mist of the precursor solution was generated using a "Liquifog" piezo ultrasonic atomizer from Johnson Matthey, which uses an operating frequency of $1.6 \mathrm{MHz}$ to produce a mode droplet size of $3 \mu \mathrm{m}$. The mist was transported into the reactor via a baffle, using $\mathrm{N}_{2}$ gas at a constant flow-rate of $1.0 \mathrm{~L} \mathrm{~min}^{-1}$. The exhaust of the reactor was vented into a fume cupboard. When the precursor solution and associated aerosol mist had been completely emptied from the bubbler, the coated substrate was cooled to below $100{ }^{\circ} \mathrm{C}$ under a continuous flow of $\mathrm{N}_{2}$ gas before being removed from the reactor.

\subsection{Analysis Techniques}

The crystal structure of the films was analysed using a Bruker GADDS D8 Lynxeye diffractometer. A Cu-K $\alpha$ X-ray source was used to take X-ray diffraction patterns over a 


\section{WILEY-VCH}

range $10-66^{\circ} 2 \theta$. Compositional analysis of the film surfaces was done using a Thermo Scientific K-Alpha X-ray photoelectron spectrometer using a monochromatic Al-K $\alpha$ X-ray source. The optical properties of the films were examined using a Perkin Elmer Fourier Transform Lambda 950 UV-vis spectrometer over a range of 250-2500 nm. The surface morphology of the films was observed using a JEOL JSM-6301F field emission SEM at an accelerating voltage of $5 \mathrm{keV}$. The electrical properties of the films were determined using the van der Pauw method to obtain Hall effect measurements. ${ }^{[43]}$

\section{Acknowledgements}

The authors would like to thank the EPSRC for grant EP/L017709 and UCL for an impact studentship (D. B. P.).

Received: ((will be filled in by the editorial staff))

Revised: ((will be filled in by the editorial staff))

Published online: ((will be filled in by the editorial staff))

[1] I. Hamberg, C. G. Granqvist, J. Appl. Phys. 1986, 60, R123.

[2] C. G. Granqvist, Appl. Phys. A: Solids Surf. 1991, 52, 83.

[3] E. Burstein, Phys. Rev. 1954, 93, 632.

[4] T. S. Moss, Proc. Phys. Soc., London, Sect. B 1954, 67, 775.

[5] H. Kim, C. M. Gilmore, A. Piqué, J. S. Horwitz, H. Mattoussi, H. Murata, Z. H. Kafafi, D. B. Chrisey, J. Appl. Phys. 1999, 86, 6451.

[6] T. Minami, Semicond. Sci. Technol. 2005, 20, S35. 


\section{WILEY-VCH}

[7] I. A. Rauf, J. Appl. Phys. 1996, 79, 4057.

[8] Y. Sawada, C. Kobayashi, S. Seki, H. Funakubo, Thin Solid Films 2002, 409, 46.

[9] Y. Shigesato, S. Takaki, T. Haranoh, J. Appl. Phys. 1992, 71, 3356.

[10] S. A. Yousif, J. M. Abass, Int. Lett. Chem., Phys. Astron. 2013, 13, 90.

[11] Z. Banyamin, P. Kelly, G. West, J. Boardman, Coatings 2014, 4, 732.

[12] A. Ortiz, S. Lopez, E. Martinez, Sol. Energy Mater. 1989, 18, 143.

[13] A. Bhardwaj, B. K. Gupta, A. Raza, A. K. Sharma, O. P. Agnihotri, Sol. Cells 1981, 5, 39.

[14] S. Shanthi, C. Subramanian, P. Ramasamy, Mater. Sci. Eng., B 1999, 57, 127.

[15] S. Suh, Z. Zhang, W.-K. Chu, D. M. Hoffman, Thin Solid Films 1999, 345, 240.

[16] A. Gupta, D. K. Pandya, S. C. Kashyap, Jpn. J. Appl. Phys. 2004, 43, L1592.

[17] N. Noor, I. P. Parkin, J. Mater. Chem. C 2013, 1, 984.

[18] U.S.G.S., Mineral Commodity Summaries 2014: U.S. Geological Survey, 2014.

[19] Ü. Özgür, Y. I. Alivov, C. Liu, A. Teke, M. A. Reshchikov, S. Doğan, V. Avrutin, S. J. Cho, H. Morko, J. Appl. Phys. 2005, 98, 1.

[20] Y. Liu, Y. Li, H. Zeng, J. Nanomater. 2013, 2013, 1.

[21] P. Gondoni, M. Ghidelli, F. Di Fonzo, V. Russo, P. Bruno, J. Martí-Rujas, C. E. Bottani, a. Li Bassi, C. S. Casari, Thin Solid Films 2012, 520, 4707.

[22] S.-M. Park, T. Ikegami, K. Ebihara, Thin Solid Films 2006, 513, 90.

[23] G. Socol, D. Craciun, I. N. Mihailescu, N. Stefan, C. Besleaga, L. Ion, S. Antohe, K. W. Kim, D. Norton, S. J. Pearton, a. C. Galca, V. Craciun, Thin Solid Films 2011, 520, 1274. 


\section{WILEY-VCH}

[24] S. Kuprenaite, T. Murauskas, A. Abrutis, V. Kubilius, Z. Saltyte, V. Plausinaitiene, Surf. Coat. Technol. 2014, 271, 156.

[25] K. L. Chopra, S. Major, D. K. Pandya, Thin Solid Films 1983, 102, 1.

[26] K. Ellmer, J. Phys. D: Appl. Phys. 2001, 34, 3097.

[27] C. G. Granqvist, Sol. Energy Mater. Sol. Cells 2007, 91, 1529.

[28] S. Basharat, C. J. Carmalt, R. Binions, R. Palgrave, I. P. Parkin, Dalton Trans. 2008, 9226, 591.

[29] K. Choy, Prog. Mater. Sci. 2003, 48, 57.

[30] D. S. Bhachu, G. Sankar, I. P. Parkin, Chem. Mater. 2012, 24, 4704.

[31] M. R. Waugh, G. Hyett, I. P. Parkin, Chem. Vap. Deposisiton 2008, 14, 366.

[32] R. Wang, L. L. H. King, A. W. Sleight, J. Mater. Res. 2011, 11, 1659.

[33] M. Birkholz, Phys. Rev. B 2003, 68, 1.

[34] S. Major, A. Banerjee, K. L. Chopra, Thin Solid Films 1983, 108, 333.

[35] M. Krunks, E. Mellikov, Thin Solid Films 1995, 270, 33.

[36] J. Morales, W. L. Estrada, E. Andrade, M. Miki-yoshida, Science (80-. ). 2000, 366, 16.

[37] S. Manu, M. A. Khadar, J. Mater. Chem. C 2015, 3, 1846.

[38] S. M. Salaken, E. Farzana, J. Podder, J. Semicond. 2013, 34, 073003.

[39] S. Chen, G. Carraro, D. Barreca, R. Binions, Thin Solid Films 2014, 584, 316.

[40] T. Muranaka, T. Uehara, T. Sakano, Y. Nabetani, T. Akitsu, T. Kato, T. Matsumoto, S. Hagihara, O. Abe, S. Hiraki, Y. Fujikawa, J. Korean Phys. Soc. 2008, 53, 2897.

[41] H. Bach, D. Krause, Thin Films on Glass, Springer-Verlag Berlin Heidelberg, 2003.

[42] O. Stenzel, The Physics of Thin Film Optical Spectra: An Introduction, SpringerVerlag Berlin Heidelberg, 2005.

[43] D. G. Stavenga, Mater. Today Proc. 2014, 1, 109.

[44] H. Hung-Chun Lai, T. Basheer, V. L. Kuznetsov, R. G. Egdell, R. M. J. Jacobs, M. 


\section{WILEY-VCH}

Pepper, P. P. Edwards, J. Appl. Phys. 2012, 112, 083708.

[45] B. E. Sernelius, K.-F. Berggren, Z.-C. Jin, I. Hamberg, C. G. Granqvist, Phys. Rev. B 1988, 37, 244.

[46] S. D. Ponja, S. Sathasivam, I. P. Parkin, C. J. Carmalt, RSC Adv. 2014, 4, 49723.

[47] L. J. van der Pauw, Philips Tech. Rev. 1958, 20, 220.

[48] S. Chen, G. Carraro, D. Barreca, R. Binions, Thin Solid Films 2014, 584, 316.

[49] M. G. Nolan, J. A. Hamilton, S. O’Brien, G. Bruno, L. Pereira, E. Fortunato, R. Martins, I. M. Povey, M. E. Pemble, J. Photochem. Photobiol. A Chem. 2011, 219, 10.
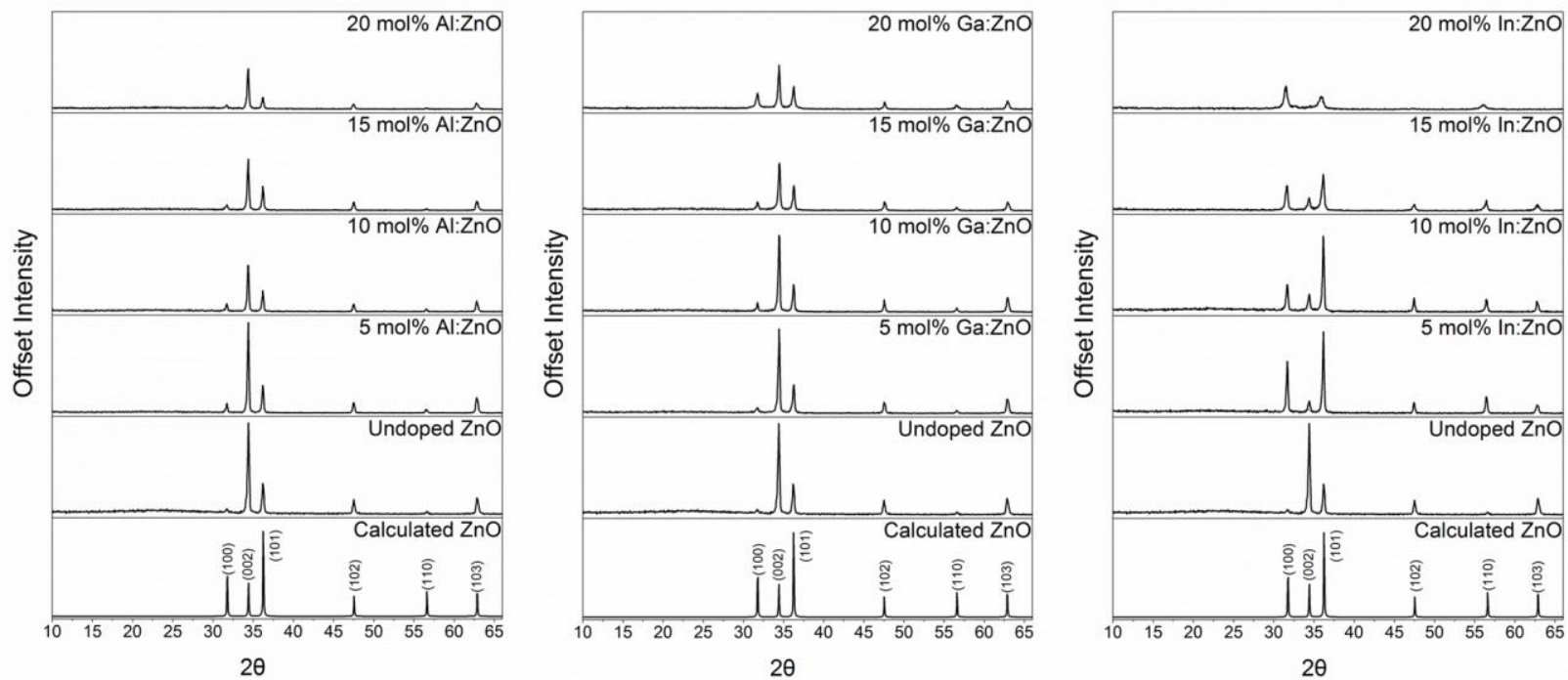

Figure 1. XRD patterns of Al-doped $\mathrm{ZnO}$, Ga-doped $\mathrm{ZnO}$, and In-doped $\mathrm{ZnO}$. 


\section{WILEY-VCH}

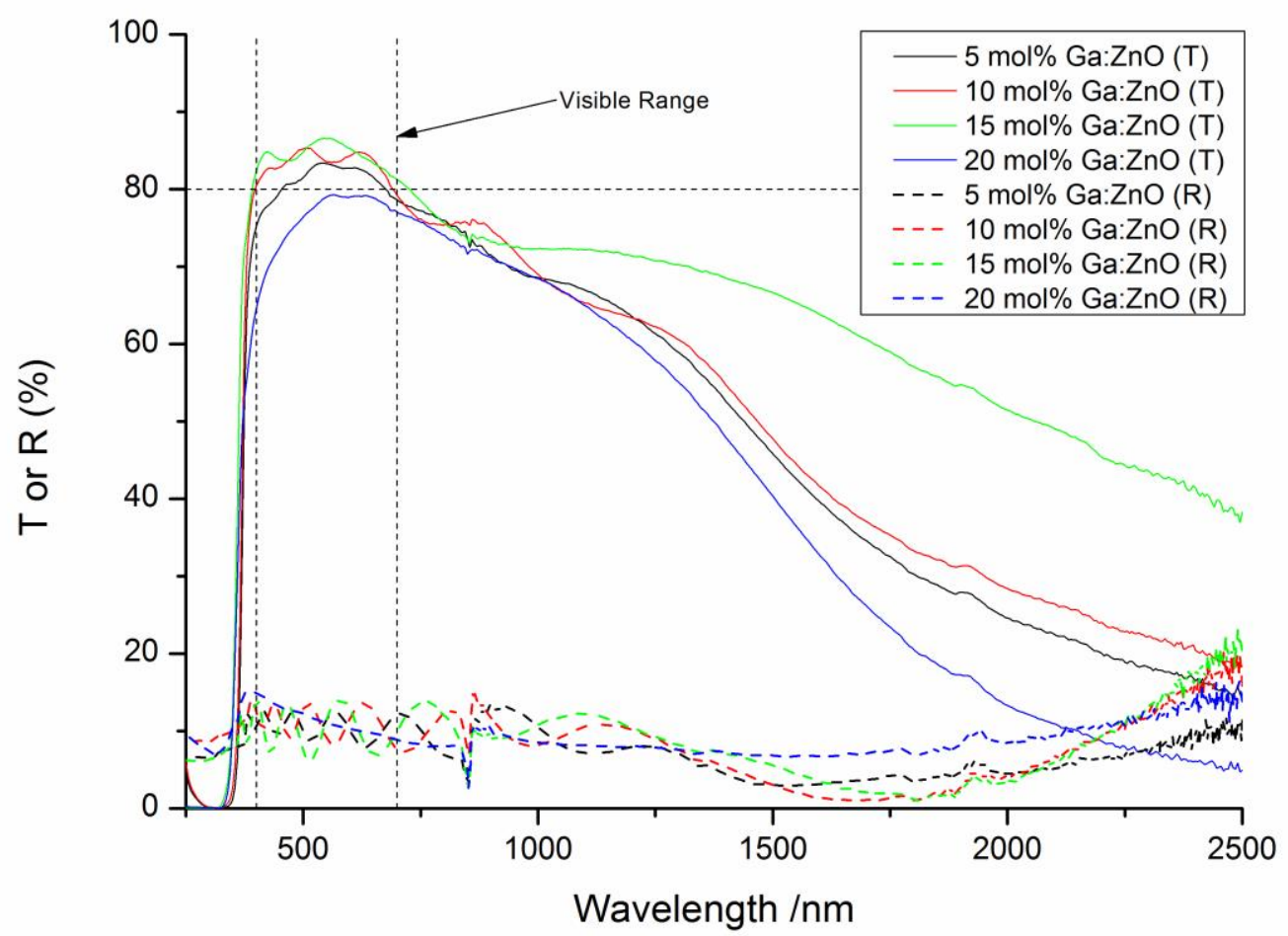

Figure 2. Transmission-reflection spectra of Ga-doped $\mathrm{ZnO}$ films.
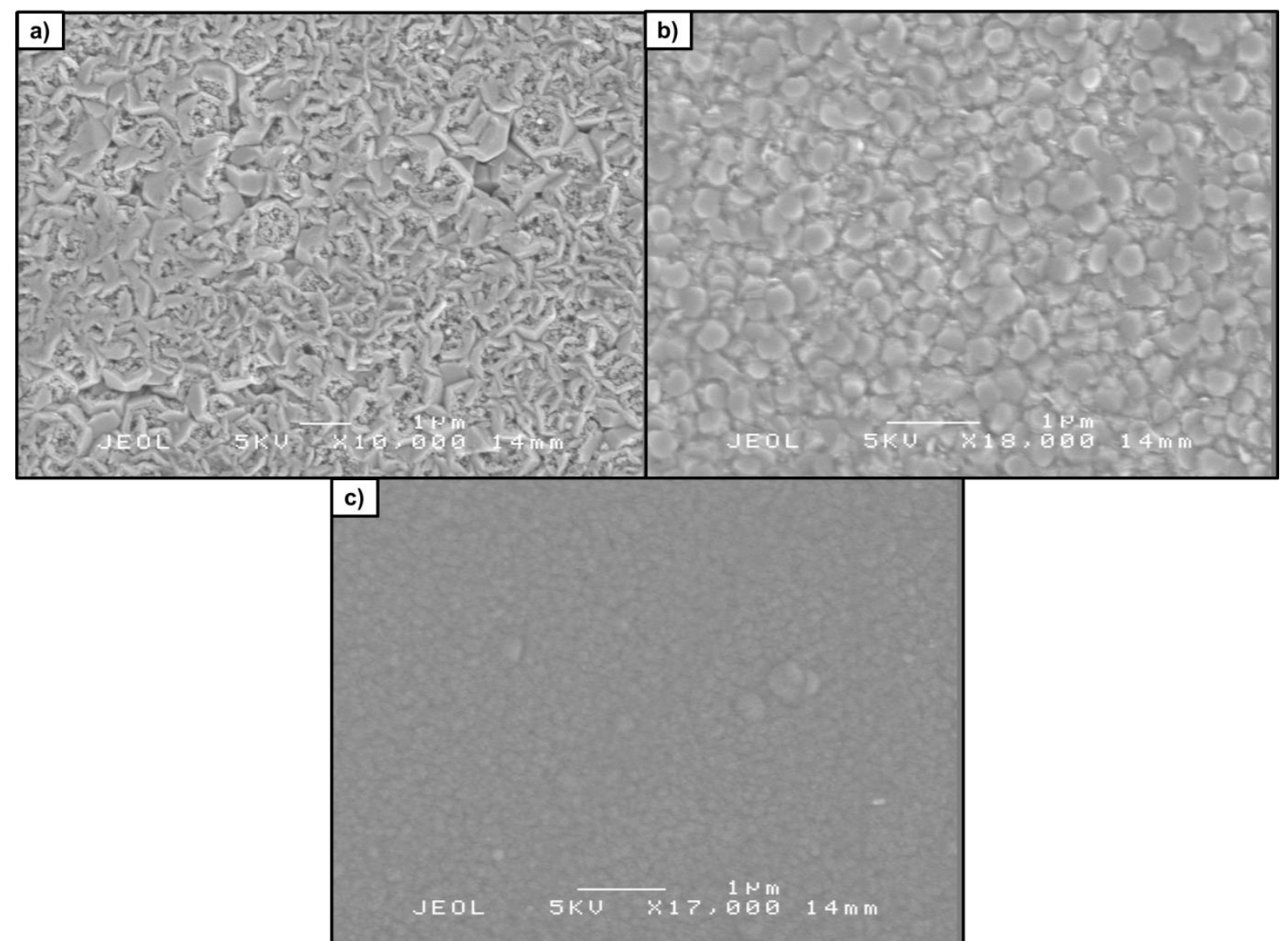

Figure 3. SEM images of a) $10 \mathrm{~mol} \%$ Al-doped $\mathrm{ZnO}$ b) $10 \mathrm{~mol} \% \mathrm{Ga}$-doped $\mathrm{ZnO}$ c) $10 \mathrm{~mol} \%$ In-doped $\mathrm{ZnO}$. 


\section{WILEY-VCH}

Table 1. Summary of properties of the doped $\mathrm{ZnO}$ films. $\rho=$ resistivity; $\mathrm{N}=$ free carrier concentration; $\mu=$ carrier mobility; $\mathrm{T}_{\lambda 400-700}=$ average transmittance over $400-700 \mathrm{~nm} ; \mathrm{E}_{\mathrm{g}}=$ band gap energy; $\mathrm{V}=$ unit cell volume (the value in parentheses is the error in the last digit); Dopant: $\mathrm{Zn}=$ dopant:zinc ratio at the film surface; $\mathrm{Cl}: \mathrm{Zn}=$ chlorine:zinc ratio at the film surface.

\begin{tabular}{|c|c|c|c|c|c|c|c|c|c|}
\hline Film & $\begin{array}{l}\rho / \times 10^{-2} \\
\Omega \cdot \mathrm{cm}\end{array}$ & $\begin{array}{l}\mathrm{N} / \mathrm{x} 10^{19} \\
\mathrm{~cm}^{3}\end{array}$ & $\begin{array}{l}\mu \\
\mathrm{cm}^{2} / \mathrm{V} \cdot \mathrm{s}\end{array}$ & $\begin{array}{l}\text { Film } \\
\text { Thickness } \\
/ \mu \mathrm{m}\end{array}$ & $\mathrm{T}_{\lambda 400-700} / \%$ & $\mathrm{E}_{\mathrm{g}} / \mathrm{eV}$ & $\mathrm{V} / \AA^{3}$ & Dopant:Zn /atm\% & $\mathrm{Cl}: \mathrm{Zn} / \mathrm{atm} \%$ \\
\hline $5 \% \mathrm{Al}: \mathrm{ZnO}$ & 0.8 & -9.72 & 8.1 & 1.0 & 78.7 & 3.25 & $47.673(5)$ & 4.8 & 1.0 \\
\hline $\begin{array}{l}10 \% \\
\mathrm{Al}: \mathrm{ZnO}\end{array}$ & 0.5 & -14.0 & 9.0 & 1.2 & 83.2 & 3.30 & $47.649(8)$ & 33.4 & 3.0 \\
\hline $\begin{array}{l}15 \% \\
\mathrm{Al}: \mathrm{ZnO}\end{array}$ & 1.1 & -12.1 & 4.7 & 2.0 & 83.6 & 3.50 & $47.620(8)$ & 73.7 & 5.6 \\
\hline $\begin{array}{l}20 \% \\
\mathrm{Al}: \mathrm{ZnO}\end{array}$ & 3.5 & -11.4 & 1.6 & 1.0 & 79.0 & 3.32 & $47.69(1)$ & 107.8 & 8.2 \\
\hline $5 \% \mathrm{Ga}: \mathrm{ZnO}$ & 3.0 & -2.12 & 9.7 & 3.8 & 81.0 & 3.28 & $47.65(7)$ & 17.2 & 1.7 \\
\hline $\begin{array}{l}10 \% \\
\mathrm{Ga}: \mathrm{ZnO}\end{array}$ & 1.3 & -6.90 & 7.1 & 2.0 & 83.4 & 3.31 & $47.573(3)$ & 16.8 & 1.0 \\
\hline $\begin{array}{l}15 \% \\
\mathrm{Ga}: \mathrm{ZnO}\end{array}$ & 2.0 & -3.15 & 10.1 & 1.9 & 84.4 & 3.37 & $47.473(8)$ & 24.7 & 1.4 \\
\hline $\begin{array}{l}20 \% \\
\mathrm{Ga}: \mathrm{ZnO}\end{array}$ & 3.3 & -2.84 & 6.6 & 2.2 & 76.2 & 3.33 & $47.520(8)$ & 32.8 & 3.3 \\
\hline $5 \% \mathrm{In}: \mathrm{ZnO}$ & 1.8 & -11.7 & 3.0 & 0.8 & 75.2 & 3.30 & $48.015(6)$ & 1.8 & 3.6 \\
\hline $10 \% \mathrm{In}: \mathrm{ZnO}$ & 1.7 & -7.28 & 5.1 & 2.0 & 77.6 & 3.33 & $47.544(6)$ & 1.3 & 1.6 \\
\hline $15 \% \mathrm{In}: \mathrm{ZnO}$ & 2.1 & -6.92 & 4.3 & 2.4 & 82.9 & 3.33 & 47.811(9) & 14.9 & 3.6 \\
\hline $20 \% \mathrm{In}: \mathrm{ZnO}$ & 22 & -2.41 & 1.2 & 1.5 & 74.3 & 3.10 & $47.578(9)$ & 18.7 & 4.0 \\
\hline
\end{tabular}

